\title{
DIELECTRIC RELAXATION PHENOMENA IN PARAELECTRIC PHASE OF NANOCRYSTALLINE-TRIGLYCINE SULFATE COMPOSITE
}

\author{
NGUYEN HOAI THUONG ${ }^{1}$, MAI BICH DUNG ${ }^{2}$, TRAN THANH NGOC ${ }^{1}$, NGUYEN THI LAN \\ HUONG $^{2}$, NGUYEN THI KIM ANH ${ }^{2}$, DOAN VAN DAT ${ }^{3}$, TA DINH HIEN ${ }^{4}$ \\ ${ }^{1}$ Faculty of Electrical Engineering Technology, Industrial University of Ho Chi Minh City \\ ${ }^{2}$ Institute of Biotechnology and Food Technology, Industrial University of Ho Chi Minh City \\ ${ }^{3}$ Faculty of Chemical Engineering, Industrial University of Ho Chi Minh City \\ ${ }^{4}$ Faculty of Electrical and Electronics Engineering Technology, Ho Chi Minh City University of Food \\ Industry \\ nguyenthuongfee@iuh.edu.vn
}

\begin{abstract}
The aim of this work is to clarify dielectric relaxation phenomena in paraelectric phase of composites based on nanocrystalline cellulose and triglycine sulfate. Although the dielectric properties of this material were almost thoroughly investigated, but there has been no study devoted to relaxation anomalies in paraelectric phase. The results showed the presence of Debye-like relaxation at the entire studied frequency range $10^{3}-10^{6} \mathrm{~Hz}$ under a weak electric field of $1 \mathrm{~V} \cdot \mathrm{m}^{-1}$ from phase transition temperature in the composite $\left(54{ }^{\circ} \mathrm{C}\right)$ to $90{ }^{\circ} \mathrm{C}$. In addition, the phenomena were observed at lower frequencies as compared to those of triglycine sulfate single crystals. The results were explained by the assumption based on critical slowing down occurred in the nanoparticles in the composite.

Keywords. ferroelectric nanocomposites, nanocrystalline cellulose, paraelectric phase, triglycine sulfate, critical slowing down.
\end{abstract}

\section{INTRODUCTION}

Materials are vital for manufacturing equipment and tools in general and electronic devices in particular. A modern technological revolution has never separated from process of developing advanced materials with smarter properties while decreasing the material size to nanoscale level. Ferroelectric nanocomposites are one of such materials. These composites contain ferroelectric nanoparticles possessing abnormal and useful properties such as the change in phase transition temperature and relaxation frequencies, the strong dielectric dispersion at low frequencies as compared to those of ferroelectrics at normal scales or disappearance of ferroelectric nature at particle critical size [1]. All the indicated phenomena have been explained by size effects and the interaction between particles by themselves as well as between the particles and matrix nanochannel walls [1-7]. It should be noted that the influence of matrix on nanocomposite properties plays an important role and cannot be negligible. Recently, the utilization of new matrices originated from nature in the field of electronics engineering has been encouraged because of their low-cost and eco-friendly advantages. That's why nanocrystalline cellulose (NCC) was chosen as a promising matrix for developing composites with triglycine sulfate (TGS) inclusion. Nanocrystalline cellulose can be used as a promising matrix for preparing nanocomposites thanks to a large number of $50-100 \mathrm{~nm}$ nanochannels [8-10], on walls of which the hydroxyl group $\mathrm{OH}^{-}$always present and are ready for the formation of hydrogen bonds with hydrogencontaining compounds as TGS nanoparticles in this case. TGS is a well-known classical ferroelectric used for a wide range of practical applications in electronics.

It is necessary to make a review over works which were already published in literature devoted to dielectric properties of composites from nanocrystalline cellulose (NCC) and triglycine sulfate (TGS). This material was synthesized for the first time by our group 5 years ago [2]. It was shown that the phase 
transition temperature in TGS nanoparticles shifted to higher temperatures as compared to those of triglycine sulfate at normal size by $5-9{ }^{\circ} \mathrm{C}[2-4]$. Another study at low and infralow frequencies $\left(10^{-3}-\right.$ $10^{3} \mathrm{~Hz}$ ) indicated the presence of strong dielectric dispersion in the composite according to the MaxwellWagner-Sillars polarization [5]. At higher frequencies $\left(10^{3}-10^{6} \mathrm{~Hz}\right)$ in ferroelectric phase, the dielectric relaxation is controlled by irreversible and reversible domain-wall motion [6]. It was also found in [6] that the relaxation point was detected at frequencies lower than that of TGS single crystals due to the increase in viscous coefficient caused by the strong interaction between TGS and NCC through hydrogen bounds. In addition, NCC is a hydrophilic material and able to adsorb water molecules from the air even under normal conditions. As a result, the properties of NCC+TGS composites were significantly changed under the influence of moisture with the increase in dielectric permittivity and dielectric loss in the studied frequency range from $10^{-3}$ to $10^{6} \mathrm{~Hz}$ in weak electric field [7].

Although the properties of NCC+TGS were almost thoroughly investigated, the dielectric dispersion in paraelectric phase i.e. at temperatures higher than the phase transition temperature in the composite has not been studied yet. All conducted studies on relaxation properties as reported in [6] were concentrated on ferroelectric phase only. In this regard, the aim of present work is to fill this gap.

\section{MATERIAL PREPARATION AND EXPERIMENTAL METHODS}

In the present work, a matrix in the form of nanocrystalline bacterial cellulose synthesized by the procedures as reported in [8-10] was used to prepare the NCC+TGS composite. The preparation method of NCC+TGS were described in detail in previous studies [2-7] as follows. From the initial gel films of NCC water was removed by filter paper to reduce the sample thickness approximately by twice. The saturated TGS solutions heated up to $+50{ }^{\circ} \mathrm{C}$ was introduced into these NCC pieces, drop by drop in several stages, each time to complete absorption from both sides. The NCC nanochannels are perpendicular with respect to the sample surface. The prepared samples were heated to $+100{ }^{\circ} \mathrm{C}$, kept for 3 hours at this temperature to completely remove residual water and then dried at room temperature. The obtained composite films with an average thickness of $\sim 0.35 \mathrm{~mm}$ were cut into samples with a surface area of $\sim 35 \mathrm{~mm}^{2}$. Twenty composite samples of were synthesized, ten of them were chosen to characterize to ensure the successful synthesis, five samples were used for testing phase transition, and two of these five samples were utilized for the study on dielectric relaxation. The samples were always stored inside a storage cabinet to prevent the pervasion of moisture that may damage the samples.

Dielectric measurements were carried out by using an Impedance/Gain-Phase Analyzer (SOLARTRON 1260A) in a weak electric field with an amplitude of $1 \mathrm{~V} \cdot \mathrm{cm}^{-1}$ from $10^{3}$ to $10^{6} \mathrm{~Hz}$. Firstly, the samples were heated to $100{ }^{\circ} \mathrm{C}$ at a heating rate of $1{ }^{\circ} \mathrm{C} \cdot \mathrm{min}^{-1}$ to remove residue water that might be adsorbed on the sample surface, and then cooled down to $54{ }^{\circ} \mathrm{C}$ at a rate of $0.5^{\circ} \mathrm{C} \cdot \mathrm{min}^{-1}$. At every temperature point of measurements, the temperature was kept for 30 minutes before measuring dielectric permittivity. The temperature stabilization was controlled better than $0.05^{\circ} \mathrm{C}$. The measurement error did not exceed $1 \%$. All data were automatically recorded on the computer. Dielectric permittivity measured in this study as a function of frequency can be expressed according to the following equation:

$$
\varepsilon^{*}(f)=\varepsilon^{\prime}(f)+i \varepsilon "(f)
$$

where $\varepsilon^{*}$ - the complex permittivity, $\varepsilon^{\prime}$ - real part of permittivity, $\varepsilon^{\prime \prime}$ - imaginary part of permittivity and $f$ measuring frequency.

\section{EXPERIMENTAL RESULTS AND DISCUSSION}

All the synthesized samples were carefully characterized by Scanning Electron Microscopy (SEM) and X-ray Diffractometry (XRD) to confirm successful synthesis of NCC+TGS composite as reported in [4, 11]. Indeed, according the characterization data, the crystalline structure of NCC component remained almost unchanged after introducing TGS nanoparticles into its nanochannels [4] and TGS particles grew into the size of $50-100 \mathrm{~nm}$ [11]. Moreover, the phase transition temperature was detected at $54{ }^{\circ} \mathrm{C} \mathrm{[6]}$, confirming ferroelectric nature of the composite. Therefore, the obtained samples are ready for further experiments in this study. 


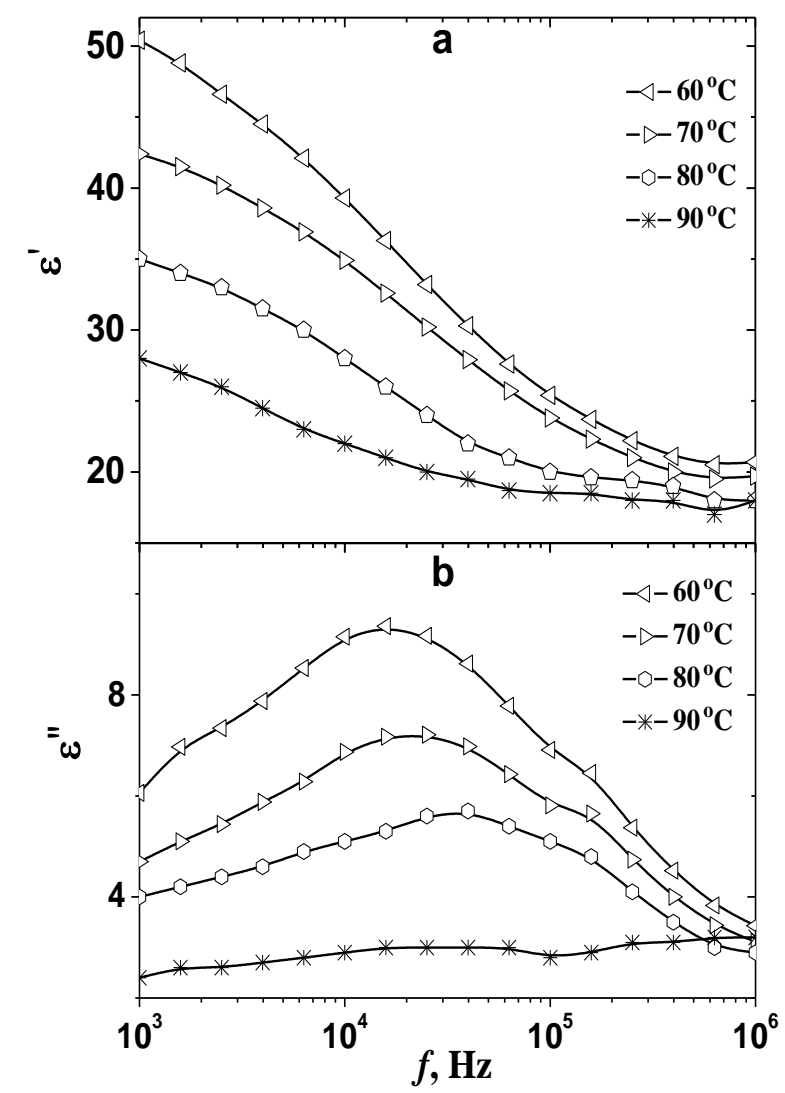

Figure 1: Frequency dependences of real (a) and imaginary (b) parts of dielectric permittivity for NCC+TGS composite.

Figure 1 shows the frequency dependences of real $\varepsilon^{\prime}(f)$ (Fig.1a) and imaginary $\varepsilon^{\prime \prime}(f)$ (Fig.1b) parts of permittivity for the composite based on TGS nanoparticles embedded into an initial dried NCC matrix. As seen in Fig. 1, the values of $\varepsilon^{\prime}$ decrease with increasing frequency at all studied temperatures while the corresponding maxima of $\varepsilon^{\prime \prime}(f)$ were detected in the range of $10^{4}-10^{5} \mathrm{~Hz}$, indicating a typical relaxation behavior for TGS single crystals. However, in the case of TGS single crystal in the vicinities of Cuire point from paraelectric phase side, the relaxation frequencies were observed at higher values of $10^{5}-10^{6}$ $\mathrm{Hz}$ [12] as compared to the results obtained in this study for NCC+TGS composite. At the same time, the relaxation frequency of the composite increased during heating (Fig. 1b), probably, indicating the activation nature of relaxation process in paraelectric phase. 

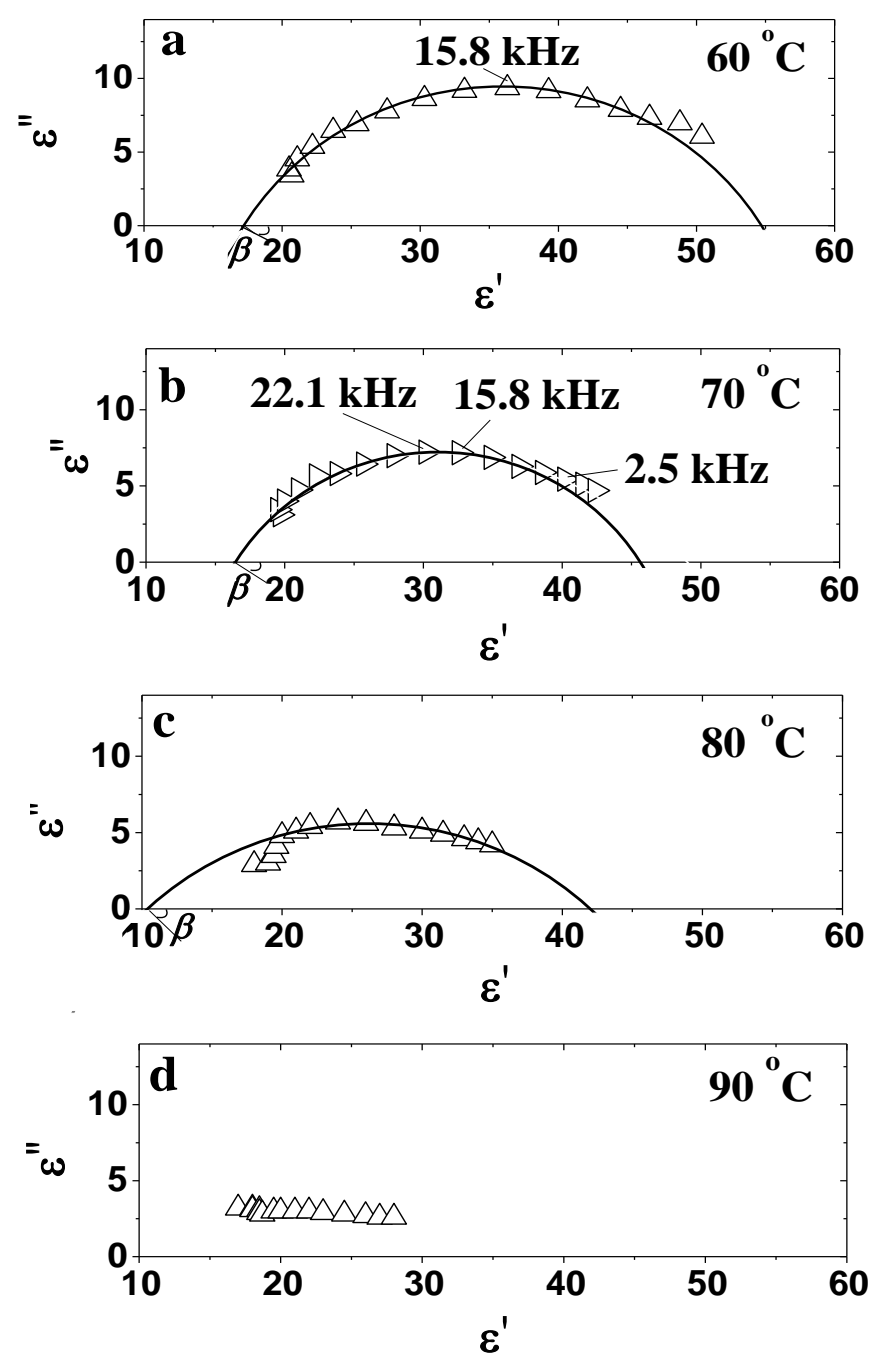

Figure 2: Cole-Cole diagrams for NCC+TGS composite at different temperatures

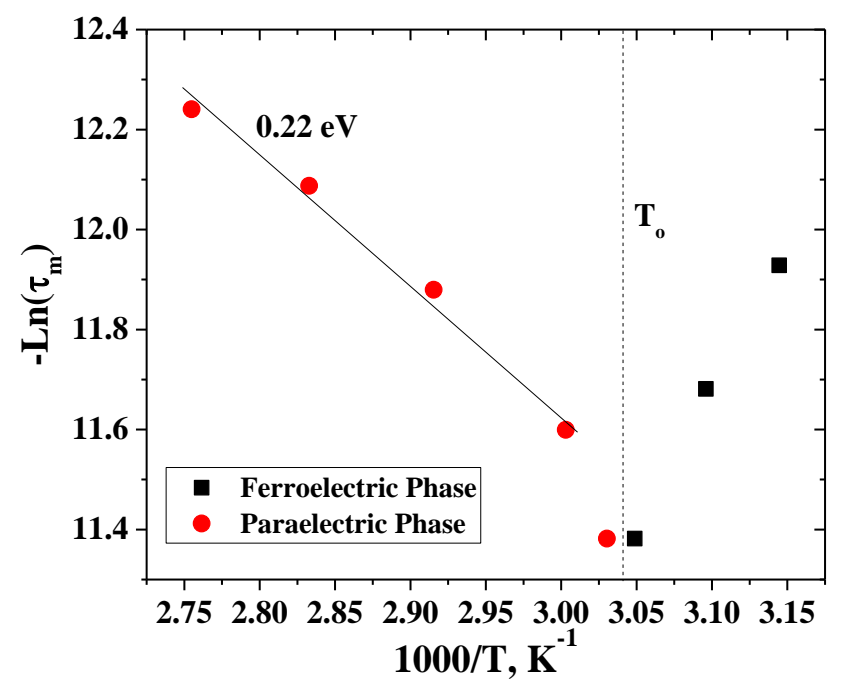

Figure 3: Dependence of relaxation time on the inverse temperature for NCC+TGS composite. 
To further clarify the relaxation mechanism for NCC+TGS composite, the Cole-Cole diagrams were plotted (Fig. 2) and the inverse temperature dependence of relaxation time was also determined (Fig. 3). It can be seen in Fig. 2 that the relaxation data fit well with Cole-Cole semicircle. In other words, dispersion in dielectric permittivity for NCC+TGS composite has Debye-like type. Moreover, the higher the temperature, the weaker the relaxation strength. At $90{ }^{\circ} \mathrm{C}$, the dispersion no longer takes place. The relaxation time was calculated by the following formula:

$$
\tau_{m}=\frac{1}{2 \pi f_{m}}
$$

where $\tau_{m}$ - relaxation time (s), $f_{m}$ - relaxation frequency $(\mathrm{Hz})$ taken from the frequencies corresponding to the maxima of $\varepsilon^{\prime \prime}(f)$. Figure 3 shows relaxation times in not only paraelectric phase, but also ferroelectric phase near the transition phase temperature in NCC+TGS composite. Relaxation times presented here in ferroelectric phase were taken from previous study [6] with the purpose of comparison. It is obviously seen that the relaxation time sharply increased in the vicinities of phase transition in the composite. After the phase transition takes place, an increase in temperature leads to a decrease in relaxation time. This behavior is in a good agreement with those of TGS single crystals [13]. Far away from phase transition point in paraelectric phase, the inverse temperature dependence of relaxation time is linear (Fig. 3) i.e. obeys Arrhenius equation:

$$
\tau_{m}=\tau_{o} \exp \left(\frac{\Delta E}{T}\right)
$$

where $\tau_{m}$ - relaxation time (s) as mentioned above, $\tau_{0}$ - a material dependent pre-exponential factor (s), $\Delta \mathrm{E}$ - activation energy $(\mathrm{J}), \mathrm{T}-$ temperature $(\mathrm{K})$. The activation energy was determined as $0.22 \mathrm{eV}$, much higher than that of TGS single crystals $(0.02 \mathrm{eV})$ [14].

The observed Debye-like relaxation, which is characteristic for TGS single crystals at normal size in the studied frequency range, is the clearest evidence for the relaxation response of TGS nanoparticles in NCC+TGS composite. The relaxation mechanism of TGS nanoparticles at paraelectric phase can be related to the critical slowing down typical for the order-disorder type of ferroelectrics as TGS due to the order at long distance in their nanoparticle lattice [15]. However, the critical slowing down occurred in TGS in the vicinities of Cuire point $\left(\Delta \mathrm{T}=\mathrm{T}-\mathrm{Tc} \approx \pm 2{ }^{\circ} \mathrm{C}\right)[13,15]$ only. In the case of NCC+TGS, the paraelectric phase region is strongly expanded to about $36{ }^{\circ} \mathrm{C}$ higher than transition point $\left(\mathrm{T}_{\mathrm{o}}=54{ }^{\circ} \mathrm{C}\right)$, probably, due to the diversity of TGS nanoparticle states by means their interactions with NCC nanochannel walls through hydrogen bond system. As a result, the order of long distance of in the lattice of every TGS nanoparticle could be slowly changed under the alternating electric field, leading to prolonging dielectric dispersion in the composite. Moreover, the slow motion of electric dipoles in TGS nanoparticles can be attributed to the reduction of relaxation frequencies and to the increase in activation energy.

\section{CONCLUSIONS}

The study showed relaxation phenomena for the composite based on NCC and TGS in paraelectric phase at low frequency range from $10^{3}-10^{6} \mathrm{~Hz}$. According to the obtained results, relaxation frequencies for TGS nanoparticles shifted to the range of lower frequencies, the relaxation region is strongly expanded and the dielectric relaxation has activation nature with the relatively high activation energy as compared to that of single crystals TGS at normal size. The relaxation mechanism was controlled by critical slowing down related to the order at long distance in TGS nanoparticle lattice due to the strong interaction between ferroelectric inclusion and nanochannel walls of NCC matrix. Overall, the obtained results help us to better understand processes occurred at phase transition of nanosized ferroelectrics. However, a huge drawback of the composite is related to difficulties in determining the TGS content embedded into nanochannels of NCC. This issue will be solved in latter studies. 


\section{ACKNOWLEDGMENT}

The study was supported by Russian Science Foundation, Project N 14-12-00583.

\section{REFERENCES}

[1] C. L. Wang, B. D. Qu, P. L. Zhang, W. L. Zhong, The stability of ferroelectric phase near critical size. Solid State Commun., vol. 88, pp. 735-737, 1993.

[2] S. D. Milovidova, O. V. Rogazinskaya, A. S. Sidorkin, H. T. Nguyen, E. V. Grohotova and N. G. Popravko, Dielectric properties of composites based on nanocrystalline cellulose and triglycine sulfate, Ferroelectrics, vol. 469, pp. 116-119, 2014.

[3] H. T. Nguyen, S. D. Milovidova, A. S. Sidorkin and O. V. Rogazinskaya, Dielectric properties of composites based on nanocrystalline cellulose with triglycine sulfate. Phys. Solid State, vol. 57, pp. 503-506, 2015.

[4] H. T. Nguyen, A. S. Sidorkin and S. D. Milovidova, Dispersion of Dielectric Permittivity in a Nanocrystalline Cellulose-Triglycine Sulfate Composite at Low and Ultralow Frequencies, Phys. Solid State, vol. 60, pp. 559$565,2018$.

[5] H. T. Nguyen, A. S. Sidorkin, S. D. Milovidova and O. V. Rogazinskaya, Electrophysical properties of matrix composites nanocrystalline cellulose - triglycine sulfate, Ferroelectrics, vol. 512, pp. 71-76, 2017.

[6] H. T. Nguyen, A. S. Sidorkin, S. D. Milovidova and O. V. Rogazinskaya, Investigation of dielectric relaxation in ferroelectric composite nanocrystalline cellulose - triglycine sulfate, Ferroelectrics, vol. 498, pp. 27-35, 2016.

[7] H. T. Nguyen, A. S. Sidorkin, S. D. Milovidova and O. V. Rogazinskaya, Influence of humidity on dielectric properties of nanocrystalline cellulose - triglycine sulfate composites, Ferroelectrics, vol. 501, pp. 180-186, 2016.

[8] Yu. G. Baklagina, A. K. Khripunov, A. A. Tkachenko, S. V. Gladchenko, V. K. Lavrentev, A. Ya. Volkov, V. K. Nilova, V. M. Denisov, T. E. Sukhanova, I. S. Zanaveskina, V. V. Klechkovskaya and L. A. Feigin, Structural Parameters of Cellulose Produced by Acetobacter Xylinum and Their Variation in the Course of Drying of Gel Films, J. Appl. Chem., vol. 76, pp. 989-996, 2003.

[9] A. K. Khripunov, A. A. Tkachenko, Yu. G. Baklagina, L. N. Borovikiva, V. K. Nilova, R. Yu. Smyslov, V. V. Klechkovskaya, N. A. Matveeva, A. Ya. Volkov, V. K. Lavrentev, M. E. Vylegzhanina, T. E. Sukhanova and V. V. Kopeikin, Formation of a composite from $\mathrm{Se}^{0}$ nanoparticles stabilized with polyvinylpyrrolidone and Acetobacter xylinum cellulose gel films, J. Appl. Chem., vol. 80, pp. 1549-1557, 2007.

[10] Yu. G. Baklagina, A. K. Khripunov, A. A. Tkachenko, V. V. Kopeikin, N. A. Matveeva, V. K. Lavrentev, V. K. Nilova, T. E. Sukhanova, R. Yu. Smyslov, I. S. Zanaveskina, V. V. Klechkovskaya and L. A. Feigin, Sorption properties of gel films of bactetial cellulose, J. Appl. Chem., vol. 78, pp. 1176-1181, 2005.

[11] H.T. Nguyen, Relaxation processes in ferroelectric composites with matrices from nanocrystalline cellulose, Thesis, 115 p., 2016.

[12] A. M. Lotonov, V. K. Novik and N. D. Gavrilova, About dispersion in dielectric permittivity of triglycine sulfate (TGS) ferroelectric in a large temperature interval, Moscow University, vol. 5, pp. 27-32, 2006.

[13] N. M. Galiyarova, Critical slowing down off relaxing domain walls and interfaces in phase transition vicinities, Ferroelectrics, vol. 170, pp. 111-121, 1995.

[14] G. Luther, Dielectric dispersion of TGS, J. Phys. Coll., vol. 33, pp. 221-222, 1972. 
[15] H. V. Alexandru and C. Berbecaru, Fundamentals in ferroelectric transition of TGS, Mater. Sci. Semicond.

Process., vol. 5, pp. 159-165, 2003.

\title{
CÁC HIÊN TƯợNG TÍCH THOÁT BÂT THƯờNG TRONG PHA THUẬN ĐIỆN CỦA VẬT LIỆU NANOCOMPOSITE TỬ TINH THỂ XENLULO VÀ TRIGLYCINE SULFATE
}

\author{
NGUYỄN HOÀI THƯƠNG ${ }^{1}$, MAI BÍCH DUNG ${ }^{2}$, TRÀ̀ THANH NGỌC ${ }^{1}$, NGUYỄN THI LAN \\ HƯƠNG ${ }^{3}$, NGUYẼ̂N THI KIM ANH ${ }^{2}$, ĐOÀN VĂN ĐẠT ${ }^{3}$, TẠ ĐİNH HIẾN ${ }^{4}$ \\ ${ }^{1}$ Khoa Công Nghệ Điện, Đại Học Công Nghiệp TP. HCM \\ ${ }^{2}$ Viện Công Nghệ Sinh học và Thưc Phẩm, Đại Học Công Nghiệp TP. HCM \\ ${ }^{3}$ Khoa Công Nghệ Hóa Họ, Đại Học Công Nghiệp TP. HCM \\ ${ }^{4}$ Khoa Công Nghệ Điện-Điện Tử, Đại Học Công Nghiệp Thưc Phẩm TP. HCM \\ nguyenthuongfee@iuh.edu.vn
}

Tóm tắt. Mục tiêu của bài báo là nhằm làm rõ các hiện tượng tích thoát bất thường trong pha thuận điện của vật liệu composite được cấu thành từ nanoxenlulo và triglycine sulfate. Mặc dù các tính chất điện của vật liệu này đã được nghiên cứu khá đầy đủ, tuy nhiên hiện tại chưa có nghiên cứu nào đề cập đến những hiện tượng tích thoát bất thường trong pha thuận điện. Các kết quả cho thấy rằng hiện tượng tích thoát có dạng chuấn Debye trong toàn dãy tần số từ $10^{3}-10^{6} \mathrm{~Hz}$ dưới điện áp yếu $1 \mathrm{~V} \cdot \mathrm{m}^{-1}$ từ nhiệt độ chuyển pha $\left(54{ }^{\circ} \mathrm{C}\right)$ đến $90^{\circ} \mathrm{C}$. Thêm vào đó, những hiện tượng bất thường này được tìm thấy ở tần số thấp hơn so với đơn tinh thể triglycine sulfate. Các kết quả nghiên cứu được giải thích dựa trên giả thuyết về sự tồn tại của sự chuyển động chậm tới hạn trong các hạt nano trong vật liệu.

Từ khóa. ferroelectric nanocomposites, nanocrystalline cellulose, paraelectric phase, triglycine sulfate, critical slowing down.

Ngày nhận bài:22/03/2018

Ngày chấp nhận đăng:03/09/2018 